\title{
Durability Studies on Glass Fibre Reinforced Self Compacting Concrete
}

\author{
Ch. Sukesh Kumar ${ }^{1}$ and Dr. M.V. Seshagiri Rao ${ }^{2}$ \\ ${ }^{1}$ M. Tech Student, CVR College of Engineering/Civil Engg. Department, Hyderabad, India. \\ Email: sukeshkumar124@gmail.com \\ ${ }^{2}$ Professor, CVR College of Engineering/ Civil Engg. Department, Hyderabad, India. \\ Email: rao_vs_meduri@yahoo.com
}

\begin{abstract}
The paper presents durability properties of Glass Fibre Reinforced Self Compacting Concrete (GFRSCC) of different grades. The durability of Glass Fibre Reinforced Self Compacting Concrete (GFRSCC) using anti-crack highly dispersible glass fibres is reported in terms of acid resistance, surface absorption and sorptivity. The mixes were designed using rational mix design procedure for SCC satisfying the EFNARC (2005) guidelines. In the first phase the mechanical properties of different grades are studied. In the second phase durability properties like Acid attack factors, Acid-Durability factors, sorptivity are studied for the Plain SCC(SCCP) and Glass Fibre Reinforced SCC(GFRSCC) and a comparison is made. Based on the studies it is observed that the compressive strengths of the GFRSCC were found to be about $10 \%$ more compared to SCCP. With the increase in the grade of concrete, the sorptivity of GFRSCC is found to be reducing. With the increase in duration of exposure to the acidic environment the ASLF increased. SCCP and GFRSCC have shown more or less similar percentage loss in strength for the same grade of concrete. With increase in period of immersion of the concrete in various solutions (acids and sulphates), there was a considerable damage of concrete near the corners of the standard cube and such disruption in GFRSCC was less than in SCCP. Overall, the GFRSCC was found to be more durable against both acids and sulphates.
\end{abstract}

Index Terms: Glass Fibres, Durability, Sorptivity and, Self Compacting Concrete, Acid attack factor, Acid durability factor

\section{INTRODUCTION}

Self compacting concrete is a self consolidating concrete defined as a Concrete which is able to flow under its self weight and to fill the formwork in complete, even in the presence of dense reinforcement, without using any vibration, whilst maintaining homogeneity. Self-compacting concrete is not affected by the shape and quantum of reinforcing bars. Professor Hajime Okamura (1997) proposed the concept of self compacting concrete in 1986, but the prototype was first developed in 1988 in Japan, by Professor Ozawa (1989). This concrete was developed to improve the durability characteristics of concrete structures. However, the Bureau of Indian Standards (BIS) has not brought out any standard mix procedure although number of agencies and researchers carried out extensive investigations to establish rational mix design procedures and testing methods in fresh state. SCC consists of materials like in conventionally vibrated concrete, which are cement, aggregates and water, with the addition of mineral and chemical admixtures in suitable proportions.
Usually, the chemical admixtures such as high-range of water reducers (Super Plasticizer) and Viscosity Modifying Agents, which change the rheological properties of concrete are used. Mineral admixtures are used as an extra fine material besides cement. In this study cement content was partially replaced with fly ash. In this study anti crack highly dispensable glass fibres are mixed to make GPRSCC and its strength and durability properties are investigated.

\section{LITERATURE REVIEW}

W Zhu et al. [1] discussed about Durability of Self Compacting Concrete. In his study, gas permeability, capillary water absorption and chloride diffusivity, which are important indicators for concrete durability performance of SCC and vibrated concrete mixes were obtained and compared.

Self compacting concrete mixes have shown low values of coefficient of permeability and sorptivity, when compared to the normal mixes of the same grade. SCC have mixes also shown chloride diffusivity similar to that of vibrated concrete mixes.

The chloride diffusivity was found to be dependent on the different types of powders used in concrete. Among the different mixes of SCC, the mixes containing less powder along with VMA to maintain stability of fresh mix have shown more permeability, chloride diffusivity and sorptivity showing less resistant for the ingress of fluids.

S Venkateswara Rao et al. [2] studied the durability performance of Self-compacting concrete. A total of three grades of concrete ie.M20, M30 and M70 grades, representing ordinary, standard, and high strength concrete, respectively were investigated.

In this study, the durability aspects of NC and SCC like acid attack, acid durability factors, thermal cycle effect, test for corrosion resistance, tests for sorptivity were investigated and concluded that with the increase in duration of exposure to the acidic nature, the ASLF was increased for both $\mathrm{NC}$ and SCC. With increase in period of immersion of concrete in various solutions (HCL, H2SO4), there was a considerable disruption of the concrete near the corners of the standard cube and such disruption in SCC was less than to NC. The 
thermal studies indicates that fly ash based SCC mixes of higher grades are performed better compared to NC The corrosion performance was better in $\mathrm{SCC}$ when compared to the NC.

SCC and NC showed more or less similar percentage loss in strength for the same grade of concrete. The weight loss was greater in NC than in SCC. The average ADLF is greater in NC for all grades than in SCC mixes. Average ADLF may be considered a unified parameter to quantify Thermal studies indicated that the fly ash-based SCC mixes of higher grades performed better than $\mathrm{NC}$ of identical grade.

$\mathrm{K}$ Rajesh Kumar et al. [3] investigated the experimental Studies on the Strength, durability and structural behaviour of beam specimens of SCC incorporating E-Glass Fiber Strands.

$\mathrm{N}$ Venkat Rao et al.. explained about an Experimental Study on Durability of High Strength Self Compacting Concrete (HSSCC). The test specimens of $10 \mathrm{~cm} \times 10 \mathrm{~cm} \times$ $10 \mathrm{~cm}$ cubes were immersed in $5 \%$ of Sodium Sulphate solution over a period of time. The performance and properties of concrete can be affected by Sulphate attack was identified. The intensity of attack by $\mathrm{H}_{2} \mathrm{SO}_{4}$ is comparatively more than the attack of $\mathrm{HCL}$ and $\mathrm{Na}_{2} \mathrm{SO}_{4}$ on the specimens.

V Karthik et al. [4] presented the study on Durability Properties of Self Compacting Concrete with Copper Slag Partially replaced for Fine Aggregate. In this investigation one control and five SCC mixes with various proportions of fine aggregate partially replaced by copper slag were prepared as per EFNARC guidelines. From the experimental results it may be concluded that copper slag at $60 \%$ replacement for fine aggregate gives the optimum results for strength and durability.

S Shrihari et al. [5] developed Strength and Durability properties of SCC with GBFS and Meta Kaolin. In this paper apart from mechanical properties, rapid chloride ion permeability and water absorption were conducted by using Meta Kaolin, GBFS and increasing percentage of fly ash with. An improvement in the impermeability, compressive and split tensile strengths were reported. Percentage of water absorption gradually decreases with the use of GIBFS with Meta Kaolin. The replacement of cement by MK leads to decrease in pore space

\section{EXPERIMENTAL PROGRAMMe}

The experimental programme consisted of casting and testing SCC specimens. The mixes were designed with rational mix design method and several trials were made in producing SCC satisfying the mixes satisfying EFNARC specifications (EFNARC, 2005). A total of four grades of concrete was investigated: M20, M30, M40 and M60 grades, representing ordinary, standard and high strength concrete, respectively according to IS 456-2000 (BIS, 2000). A total of 40 standard cubes of size $150 \mathrm{mmX} 150 \mathrm{mmX} 150 \mathrm{~mm}$ for SCCP, 40 standard cubes for GFRSCC for acid attack, sulphate attack and eight specimens each for SCCP and
GFRSCC of size $100 \mathrm{~mm} \times 100 \mathrm{~mm}$ for sorptivity studies, were cast and tested.

\section{MATERIALS ANd Properties}

\section{Cement}

OPC of 53 grade is used in the investigation. The Cement used was tested as per IS 4031-1988 and found to be satisfying the specifications of 12269-1987.The specific gravity was 3.1 and fineness was $2.37 \%$.

\section{Coarse Aggregate}

Crushed granite metal of $10 \mathrm{~mm}$ size from a local source was used as coarse aggregate. The specific gravity and fineness modulus were 2.64 and 6.6 respectively.

\section{Fine Aggregate}

River sand was used as fine aggregate. The specific gravity is 2.59 and fineness modulus is 2.83 .

\section{Fly Ash}

Type-II fly was used in the investigations. The properties of fly ash is confirming to I.S. $3812-1981$.

\section{Glass Fibres}

Anti Crack High Dispersion glass fibres were used in the investigation. The glass fibres have aspect ratio of $857: 1$, filament length of $12 \mathrm{~mm}$ and filament diameter of $14 \mu \mathrm{m}$ were used.

\section{Super Plasticizer}

Super Plasticizer having Relative density $1.08 \pm 0.01$ and $\mathrm{pH}$ value as $7 \pm 1$ with Chloride Content nil was used.

\section{Viscosity Modifying Agent}

Viscosity modifying agent used is colourless, free flowing liquid. It is a having Specific of gravity 1.01 $\pm 0.01 @ 25^{\circ} \mathrm{C}$ and apH value as $8 \pm 1$ with no Chloride Content.

\section{Acids and sulphates}

The properties of the constituent acids and sulphate used in the present investigation are LR (laboratory grade) hydrochloric acid 35-38\% with specific gravity $1.18 \mathrm{~kg} / 1$, LR sulfuric acid $98 \%, 98.07 \mathrm{~g} / \mathrm{mol}$ with specific gravity 1.835 $\mathrm{kg} / \mathrm{l}$ and sodium sulphate with specific gravity of 1.464 , molecular weight $142.036 \mathrm{~g} / \mathrm{mol}$ were used in this study at concentrations of both acids and sulphate is $5 \%$.

\section{MiX PROPORTIONS}

The Rational mix design methods was used (SV Rao et al., 2010). The details of the mix proportions are shown in Table 1 , The fresh properties of the four grades of concrete and the compressive strength of the four grades of concrete were shown.

\section{DURABILITY STUdIES}

Tests for acid attack and sorptivity were conducted for different grades of SCCP and GFRSCC. 


\section{Tests for acid attack on SCCP and GFRSCC}

After 28 days of water curing, each cube was tested for weight and compressive strength. The cured specimens of different grades viz. M20, M30, M40 and M60 concrete specimens were kept exposed to $5 \%$ solutions of Sulfuric acid, Hydrochloric acid and Sodium Sulphate. Cubes were immersed for 28 days and 56 days. The response of the specimens to the solutions was evaluated through change in appearance, weight, compressive strength and dimensions of solid diagonals. Before testing, each specimen was removed and brushed and cleaned with water. For determining the resistance of concrete specimens to aggressive environment such as acid attack, durability attack factors such as acid strength loss factor (ASLF), acid attacking factor (AAF), acid weight loss factor (AWLF) and acid durability loss factor (ADLF) (Venkateswara Rao, 2010) are evaluated as per ASTM C 666-1997 (ASTM, 1997).

ASLF gives relative performance of concrete before and after immersion in different of acids and Sulphates. The factor also depends on the period of immersion of the specimen in solution. ASLF can be calculated as

$$
\text { Acid strength loss factor }(A S L F)=S r \times(N / M)
$$

Where $\mathrm{Sr}$ is relative strength at $\mathrm{N}$ days $(\%), \mathrm{N}$ is number of days at which the durability factor is required; $\mathrm{M}$ is number of days at which the exposure is to be terminated. A lower value of ASLF indicates greater stability towards acid attack.

AAF is meant to determine indirectly the disruption of concrete near the corners of the cube by way of measuring the change in the length of diagonal (referred to as diagonal loss) in a typical concrete cube after immersion in acids and Sulphate for a certain period of time. The extent of loss is determined as

$$
\text { Acid attack factor }(A A F)=
$$

\section{$\frac{\text { Loss of acid diagonal after immersion }}{\text { Acid diagonal before immersion }} \times 100 \%$}

A higher value of AAF indicates that the dimensional stability is lower.

AWLF is calculated follows after immersing the cubes in different solutions for different periods.

$$
\begin{aligned}
& \text { Acid weight loss factor }(A W L F)= \\
& \frac{\text { Loss of weight of specimen after immersion }}{\text { Original weight of specimen before immersion }} \times 100 \%
\end{aligned}
$$

A higher value of the AWLF indicates that the weight loss is greater.
In order to have a unified factor describing durability, these factors are combined to derive a factor termed the ADLF.

$$
A D L F=A S L F \times A A F \times A W L F
$$

\section{Test for Sulphate Attack on SCC and GFRSCC}

Resistance of concrete to the attack has been tested by immersing concrete cubes in the solution of $5 \%$ Sodium Sulphate. The effect of chemical attack has been determined by measuring change of mass in to consideration. The test specimens of $100 \mathrm{~mm} \times 100 \mathrm{~mm} \times 100 \mathrm{~mm}$ were immersed in 5 $\%$ of Sodium Sulphate solution for different periods ie. 28 and 56 days and the effect of Sulphate attack on performance properties of concrete are obtained. The resistance of concrete to the Sulphate attack has been estimated by considering changes in their dynamic modulus of elasticity. Even from the visual observation also the intensity of Sulphate attack on disintegration is noticed.

\section{Tests for Sorptivity}

Sorptivity is transport of moisture into unsaturated specimens. Sorptivity is as an important index of concrete durability because the test method used for the determination of Sorptivity reflects the way in which different solutions will penetrate into the concrete. Sorptivity tests were carried out on cubes of size $100 \mathrm{~mm} \times 100 \mathrm{~mm} \times 100 \mathrm{~mm}$ on the basis of Hall's method (Hall, 1989).

The Sorptivity Co-efficient (s) was obtained from the expression

$$
S=i / t^{1 / 2}, i=\Delta W / A d
$$

Where $\Delta \mathrm{W}$ is the amount of water absorbed $(\mathrm{kg})^{1} ; \mathrm{A}$ is the cross-section of specimen that was in contact with water $\left(\mathrm{m}^{2}\right)$; $\mathrm{d}$ is the density of the medium in which the specimen was dipped $(\mathrm{d}=1$, as the medium used was water); $\mathrm{t}=$ time ( $\mathrm{min})$. The unit of $\mathrm{s}$ is $\mathrm{kg} /\left(\mathrm{m}^{2} \min ^{1 / 2}\right)$.

The variation of $\mathrm{i}$ against $\mathrm{t}^{1 / 2}$ was plotted.

\section{Test Results And Discussions}

The durability of different grades SCC and GFRSCC was studied. A total number of 80 cubes were casted and after 56 days of acid environment curing with distilled water. The cubes were tested for compressive strength. From the studies on acid effect on SCC and GFRSCC specimens, it was noted that most of the GFRSCC specimens performed well compared with SCC specimens. To estimate the effects of acid on SCC and GFRSCC, certain factors are determined, as explained in the following paragraphs.

\section{ADLF for SCC and GFRSCC}

When the specimens were kept in an acid environment, the net loss in strength, physical change in the dimensions of the cube and weight loss were noted. All of these can be considered to derive a unique factor typically depicting the various losses due to acid attack and termed as ADLF 
(Venkateswara Rao, 2010). The different losses are individually quantified in terms of different factors.

\section{Acid Strength Loss Factor}

The ASLF indicates the variation in the compressive strength of SCC and GFRSCC when kept in different acidic environments, namely $\mathrm{HCl}$ and $\mathrm{H}_{2} \mathrm{SO}_{4}$ at $5 \%$ concentrations. Figure 1 shows the variation of ASLF in SCC and GFRSCC for56 days of immersion in acids. The figure indicates that the SCC and GFRSCC showed more or less similar percentage loss in strength for the different grades of concrete. Furthermore, it is observed that as the strength grade increased there is a slight increase in percentage loss of strength in both SCC and GFRSCC. This can be justified by the notion that increase in strength may not bring increase in durability, as interpreted from the loss of strength. Because, it can be based on performance design rather than the strength-based design of concrete. The ASLF is less for GFRSCC than SCC for $5 \% \mathrm{HCl}$ and the rate of increase of ASLF is greater in sulfuric acid solution.

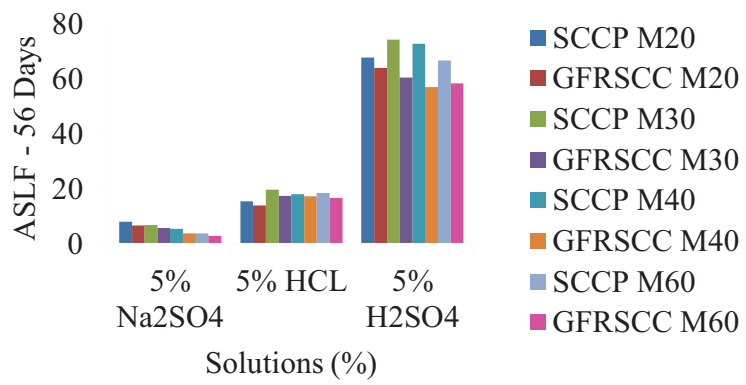

Figure 1. Acid Strength Loss Factors (ASLF) for SCCP and GFRSCC at 56 Days

\section{Acid Attacking Factor}

The AAF gives an idea of the disruption in the geometry of the specimen due to an acidic environment. This is determined by measuring the loss in the diagonals of standard test specimens. The average loss in the diagonals was measured for all the specimens immersed in acid at the end of 28 days and 56 days. Again a comparison for all the grades of concrete between SCC and GFRSCC revealed that GFRSCC specimens performed better than SCC specimens. Figure 2 shows the variation of AAF in SCC and GFRSCC for 56 days of immersion in acids. This indicates that there is less loss of diagonal (i.e. greater dimensional stability) in GFRSCC mixes than in SCC mixes. When the specimens were subjected to $\mathrm{H}_{2} \mathrm{SO}_{4}$, there was a greater loss of dimensional stability with $\mathrm{H}_{2} \mathrm{SO}_{4}$ than with $\mathrm{HCl}$.

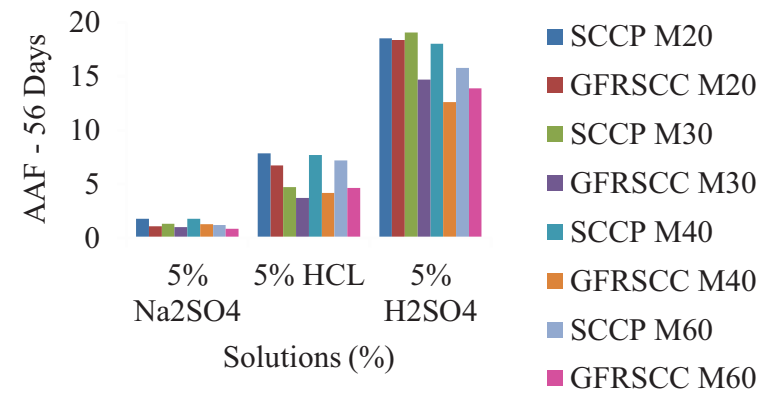

Figure 2. Acid Attack Factors (AAF) for SCC and GFRSCC at 56 days of immersion

\section{Acid Weight Loss Factor}

Because of the acidic environment, the $\mathrm{pH}$ of the concrete decreases; at the same time the cement and the mortar part in the interstices will be completely eaten away by the acid. This results in decrease in the weight of the specimen. It can be noted in general that the loss is greater with $5 \% \mathrm{H}_{2} \mathrm{SO}_{4}$ than with $\mathrm{HCl}$. Figure 3 shows the variation of AWLF in SCC and GFRSCC for 56 days of immersion in acids.

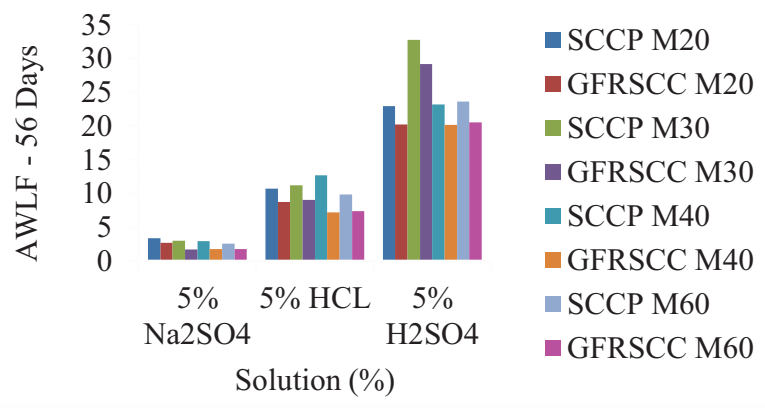

Figure 3. Acid weight loss factors (AWLF) for SCC and GFRSCC at 56 days of immersion

\section{Acid Durability Loss Factor}

The above losses in strength, weight and geometry are combined to obtain a durability factor termed ADLF. Figure 4 shows the variation of ADLF in SCC and GFRSCC for 56 days of immersion in acids. It can be noted that the losses are greater in SCC specimens than in GFRSCC specimens. Hence, it can be said at this stage that the GFRSCC specimens are more durable compared to SCC. In the present study, four grades of concrete and two types of acids $\left(\mathrm{HCl}\right.$ and $\left.\mathrm{H}_{2} \mathrm{SO}_{4}\right)$ and one type of Sulphate with concentration of 5\% were considered. The ADLF values were calculated from the loss factors of ASLF, AAF and AWLF. The average ADLF values are given in Table 2. Figure 4 shows the variation in average ADLF with acid concentration for both SCC and GFRSCC. The figure reveals that for $\mathrm{HCL}$ and $\mathrm{Na}_{2} \mathrm{SO}_{4}$ concentrations the SCC and GFRSCC behaved similarly, but as the $\mathrm{H}_{2} \mathrm{SO}_{4}$ concentration increase the SCC showed higher damage levels than GFRSCC. This indicates that the performance of GFRSCC is better than that of SCC under acidic and Sulphate environmental conditions. It also supports the use of GFRSCC in acidic and Sulphate environments. 


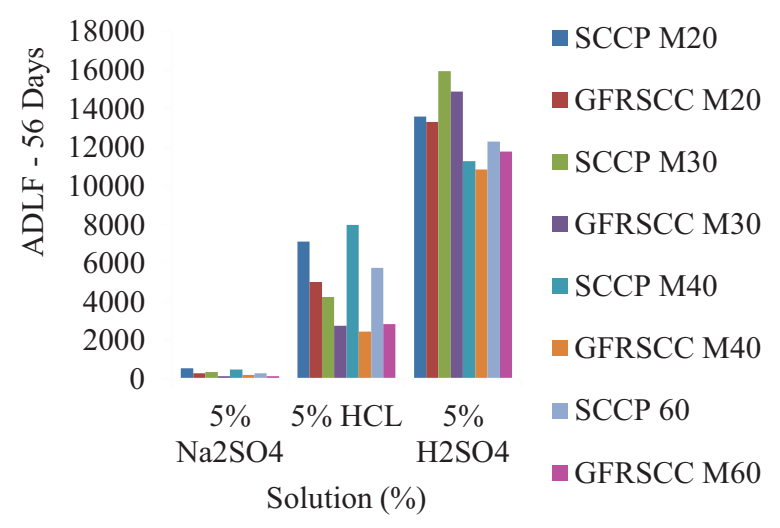

Figure 4. Acid Durability Loss Factors (ADLF) for SCCP and GFRSCC at 56 Days of immersion

\section{Sorptivity Studies on SCP and GFRSCC}

Sorptivity is the absorption and transmission of water by capillary action (Pereira de Oliveira et al., 2006). Table 3 shows the details of the water absorbed due to capillary action and Sorptivity coefficient for SCC and GFRSCC. Figures 5 $\& 6$ and show the variation of absorbed water per unit area, $\mathrm{i}$ against $\mathrm{t}^{1 / 2}$ : The cumulative water absorption was less for GFRSCC than for SCC with increasing time. This is true for all grades of concrete. For the Sorptivity coefficient, asymptotic behaviour was observed for both SCC and GFRSCC mixes. It can be noted from the above tables and figures that as the grade of concrete increases the water absorption decreases. Also, the values of water absorption in SCC are much lower than in GFRSCC.

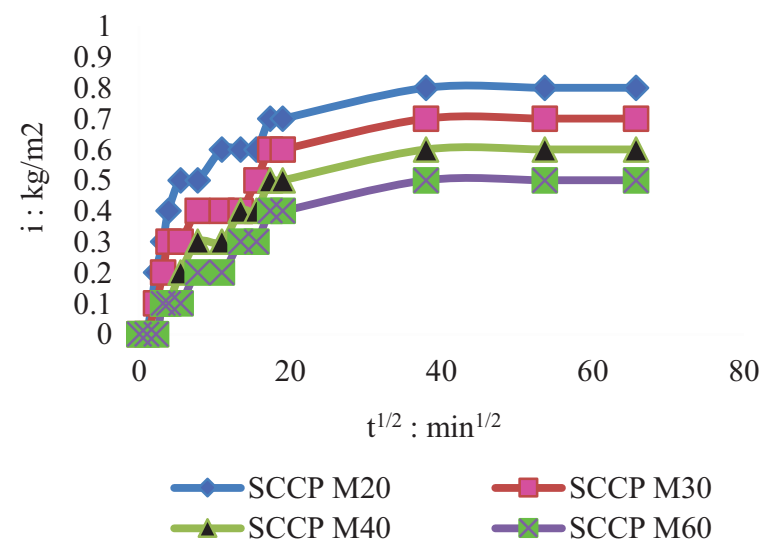

Figure 5.Absorbed water per unit area (i) against time ( $\left.\mathrm{t}^{1 / 2}\right)$ for SCCP

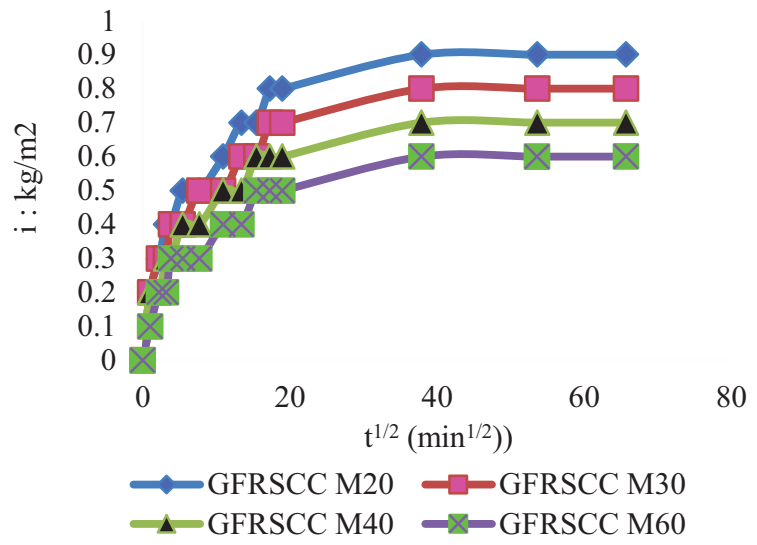

Figure 6. Absorbed water per unit area (i) against time $\left(\mathrm{t}^{1 / 2}\right)$ for GFRSCC

\section{CONCLUSIONS}

Based on the studies on SCC and GFRSCC mixes of different grades, the following conclusions are drawn

1. Fibre reinforced self-compacting concrete can be produced by adding glass fibres to improve its performance. However, the use of super plasticizer and viscosity modifying agent are essential to obtain the fresh properties of SCC.

2 . In the case of high dispersion of glass fibres, a dosage of 600 grams of fibres $/ \mathrm{m}^{3}$ of concrete is used as optimum dosage by suitably adjusting the dosage of admixtures.

3. In different grades of the concrete i.e., M20, M30, M40 and M60, the compressive strength of the Glass fibre reinforced Self-compacting concrete was found to be more, ranging from $2 \%$ to $10 \%$, when compared to plain selfcompacting concrete.

4.The increase in the grade of concrete, the Sorptivity of Glass Fibre Reinforced SCC is found to be reducing. This is same in plain SCC.

5. With the increase in duration of exposure to the acidic environment the ASLF increased. This was true for both SCCP and GFRSCC. SCCP and GFRSCC showed more or less similar percentage loss in strength for the same grade of concrete.

6. With increase in period of immersion of the concrete in various types $\left(\mathrm{Na}_{2} \mathrm{SO}_{4}, \mathrm{HCl}\right.$ and $\left.\mathrm{H}_{2} \mathrm{SO}_{4}\right)$ and $5 \%$ concentration of acid and Sulphate, there was a considerable damage of concrete near the corners of the standard cube and such disruption in GFRSCC was less than in SCCP, indicating superior durability of GFRSCC.

7. The GFRSCC has shown 3\% more resistance to weight loss, compared to plain SCC.

8. When compared to the plain SCC, the GFRSCC was found to be more durable against both acids and Sulphates. 
TABLE I.

QuANTITIES Per 1 Cum OF Self COMPacting Concretes

\begin{tabular}{|c|c|c|c|c|c|c|c|c|c|}
\hline $\begin{array}{c}\text { Grade of } \\
\text { Concrete }\end{array}$ & $\begin{array}{c}\text { Cement } \\
\left(\mathrm{kg} / \mathrm{m}^{3}\right)\end{array}$ & $\begin{array}{c}\text { Fine } \\
\text { aggregate } \\
\left(\mathrm{kg} / \mathrm{m}^{3}\right)\end{array}$ & $\begin{array}{c}\text { Coarse } \\
\text { Aggregate } \\
\left(\mathrm{kg} / \mathrm{m}^{3}\right)\end{array}$ & $\begin{array}{c}\text { Fly ash } \\
\left(\mathrm{kg} / \mathrm{m}^{3}\right)\end{array}$ & $\begin{array}{c}\text { Water } \\
\left(\mathrm{kg} / \mathrm{m}^{3}\right)\end{array}$ & $\begin{array}{c}\text { SP } \\
\% \\
\text { bwcf }\end{array}$ & $\begin{array}{c}\text { VMA } \\
\% \\
\text { Bwcf }\end{array}$ & $\begin{array}{c}\text { Glass } \\
\text { Fibre } \\
\% \\
\text { Volume }\end{array}$ & Designation \\
\hline \multirow{2}{*}{ M 20} & 258 & 900 & 685 & 309 & 240 & 1 & 0.05 & - & SCCP \\
\cline { 2 - 10 } & 258 & 900 & 685 & 309 & 240 & 1 & 0.05 & 0.024 & GFRSCC \\
\hline \multirow{2}{*}{ M 30} & 360 & 885 & 700 & 345 & 210 & 1.5 & 0.05 & - & SCCP \\
\cline { 2 - 10 } & 360 & 885 & 700 & 345 & 210 & 1.5 & 0.05 & 0.024 & GFRSCC \\
\hline \multirow{2}{*}{ M 40} & 468 & 884 & 700 & 350 & 240 & 1.5 & 0.05 & - & SCCP \\
\cline { 2 - 10 } & 468 & 884 & 700 & 350 & 240 & 1.5 & 0.05 & 0.024 & GFRSCC \\
\hline \multirow{2}{*}{ M 60} & 660 & 850 & 730 & 310 & 260 & 1 & - & - & SCCP \\
\cline { 2 - 10 } & 660 & 850 & 730 & 310 & 260 & 1 & & 0.024 & GFRSCC \\
\hline
\end{tabular}

TABLE II.

Acid Durability loss Factors Of Self Compacting Concrete MiXes

\begin{tabular}{|c|c|c|c|c|c|c|c|}
\hline \multirow{3}{*}{$\begin{array}{l}\text { Type of } \\
\text { Concrete }\end{array}$} & \multirow{3}{*}{$\begin{array}{l}\text { Grade of } \\
\text { Concrete }\end{array}$} & \multicolumn{6}{|c|}{ Acid Durability Loss Factors } \\
\hline & & \multicolumn{2}{|c|}{$\mathrm{Na}_{2} \mathrm{SO}_{4}$} & \multicolumn{2}{|c|}{ HCL } & \multicolumn{2}{|c|}{$\mathrm{H}_{2} \mathrm{SO}_{4}$} \\
\hline & & 28 Days & 56 Days & 28 Days & 56 Days & 28 Days & 56 Days \\
\hline \multirow{4}{*}{ SCCP } & 20 & 65.93 & 552.30 & 634.84 & 7114.6 & 2422.26 & 13598.2 \\
\hline & 30 & 42.27 & 362.89 & 657.37 & 4246.55 & 2044.65 & 15955.0 \\
\hline & 40 & 67.74 & 494.21 & 1227.23 & 7996.1 & 2544.9 & 11298.1 \\
\hline & 60 & 48.21 & 297.71 & 900.93 & 5768.76 & 3422.86 & 12300.6 \\
\hline \multirow{4}{*}{ GFRSCC } & 20 & 40.25 & 272.71 & 495.83 & 5023.14 & 2463.6 & 13322.6 \\
\hline & 30 & 19.82 & 160.25 & 294.68 & 2756.48 & 2397.41 & 15896.1 \\
\hline & 40 & 33.33 & 218.84 & 364.66 & 2472.27 & 3071.15 & 10868.1 \\
\hline & 60 & 11.97 & 144.07 & 382.14 & 2846.06 & 2577.07 & 10794.2 \\
\hline SCCP & \multirow{2}{*}{$\begin{array}{l}\text { Average } \\
\text { ALDF }\end{array}$} & 56.03 & 426.77 & 855.09 & 6281.5 & 2608.66 & 13287.9 \\
\hline GFRSCC & & 26.34 & 198.96 & 384.32 & 3274.48 & 2452.3 & 12220.2 \\
\hline
\end{tabular}

TABLE III.

SORPTIVITY FOR SCCP AND GFRSCC

\begin{tabular}{|c|c|c|c|c|c|c|c|c|}
\hline \multirow{2}{*}{$\begin{array}{l}\text { Time } \\
\left(\min ^{1 / 2}\right)\end{array}$} & \multicolumn{8}{|c|}{ Absorption (i) $\mathrm{kg} / \mathrm{m}^{2}$} \\
\hline & $\begin{array}{l}\text { SCCP } \\
\text { M20 }\end{array}$ & $\begin{array}{c}\text { GFRSCC } \\
\text { M20 }\end{array}$ & SCCP M30 & $\begin{array}{c}\text { GFRSCC } \\
\text { M30 }\end{array}$ & SCCP M40 & $\begin{array}{c}\text { GFRSCC } \\
\text { M40 }\end{array}$ & SCCP M60 & $\begin{array}{c}\text { GFRSCC } \\
\text { M60 }\end{array}$ \\
\hline 0 & 0 & 0 & 0 & 0 & 0 & 0 & 0 & 0 \\
\hline 1 & 0 & 0.2 & 0 & 0.2 & 0 & 0.2 & 0 & 0.1 \\
\hline 2.23 & 0.2 & 0.3 & 0.1 & 0.3 & 0 & 0.2 & 0 & 0.2 \\
\hline 3.16 & 0.3 & 0.4 & 0.2 & 0.3 & 0.1 & 0.3 & 0.1 & 0.2 \\
\hline 3.87 & 0.4 & 0.4 & 0.3 & 0.4 & 0.1 & 0.3 & 0.1 & 0.3 \\
\hline 5.47 & 0.5 & 0.5 & 0.3 & 0.4 & 0.2 & 0.4 & 0.1 & 0.3 \\
\hline 7.74 & 0.5 & 0.5 & 0.4 & 0.5 & 0.3 & 0.4 & 0.2 & 0.3 \\
\hline 10.95 & 0.6 & 0.6 & 0.4 & 0.5 & 0.3 & 0.5 & 0.2 & 0.4 \\
\hline 13.41 & 0.6 & 0.7 & 0.4 & 0.6 & 0.4 & 0.5 & 0.3 & 0.4 \\
\hline 15.49 & 0.6 & 0.7 & 0.5 & 0.6 & 0.4 & 0.6 & 0.3 & 0.5 \\
\hline 17.32 & 0.7 & 0.8 & 0.6 & 0.7 & 0.5 & 0.6 & 0.4 & 0.5 \\
\hline 18.97 & 0.7 & 0.8 & 0.6 & 0.7 & 0.5 & 0.6 & 0.4 & 0.5 \\
\hline 37.94 & 0.8 & 0.9 & 0.7 & 0.8 & 0.6 & 0.7 & 0.5 & 0.6 \\
\hline 53.66 & 0.8 & 0.9 & 0.7 & 0.8 & 0.6 & 0.7 & 0.5 & 0.6 \\
\hline 65.72 & 0.8 & 0.9 & 0.7 & 0.8 & 0.6 & 0.7 & 0.5 & 0.6 \\
\hline
\end{tabular}



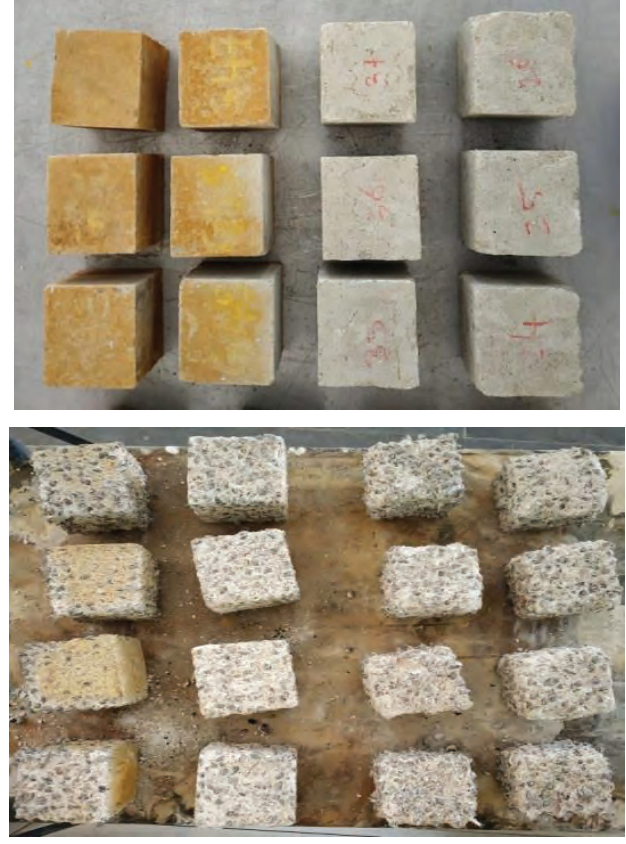

Figure 7. After Immersion of Specimens in Acids and Sulphate
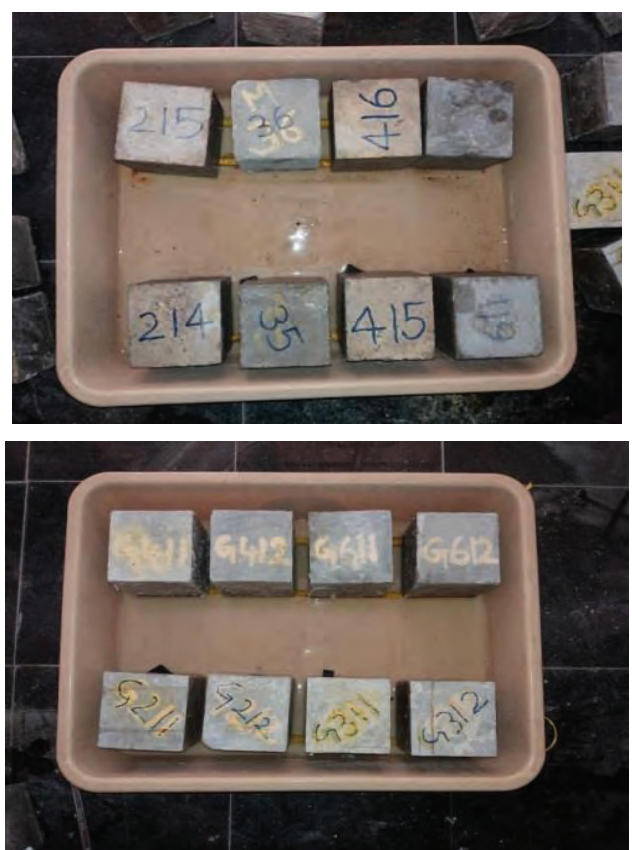

Figure 8. Testing of SCCP and GFRSCC Specimens for Sorptivity

\section{REFERENCES}

[1] W Zhu J Quinn \& PJM Bartos “Aspects Of Durability Of Self Compacting Concrete" Advanced Concrete and Masonry Centre, University of Paisley, Scotland, UK 2002.

[2] S Venkateswara Rao, M V Seshagiri Rao, D Ramaseshu, P Rathish Kumar "Durability performance of selfcompacting Concrete" Magazine of Concrete Research Volume 64 Issue 11 2012.

[3] K. Rajesh Kumar, N. Mahendran "Experimental Studies On Strength, Durability And Behaviour Of Beam Using S.C.C. With E-Glass Fiber Strands" International Journal of Engineering Research \& Technology (IJERT) Vol. 2 Issue 4, April - 2013.

[4] V Karthik and G Baskar (2015) "Study On Durability Properties Of Self Compacting Concrete With Copper Slag Partially Replaced For Fine Aggregate" International Journal Of Civil Engineering And Technology (Ijciet) Volume 6, Issue 9, Sep 2015, pp. 20-30, Article ID: IJCIET_06_09_003.

[5] S Shrihari and Seshgiri Rao M V "Strength and Durability properties of SCC with GBFS and MetaKaolin" Journal of Chemical and Pharmaceutical Sciences ISSN: 0974-2115, JCHPS Special Issue 2: August 2016.

[6] EFNARC, "Specifications and guidelines for self compacting concrete", www.efnarc.org 